\title{
Stopping when knowing: use of snus and nicotine during pregnancy in Scandinavia
}

\author{
Ina Kreyberg ${ }^{1,2}$, Karen E.S. Bains ${ }^{1,2}$, Kai-H. Carlsen ${ }^{1,2}$, Berit Granum ${ }^{3}$, \\ Hrefna K. Gudmundsdóttir ${ }^{1,2}$, Guttorm Haugen ${ }^{1,4}$, Gunilla Hedlin ${ }^{5,6}$, \\ Katarina Hilde ${ }^{1,4}$, Christine M. Jonassen ${ }^{7,8}$, Live S. Nordhagen ${ }^{1,2,9}$, \\ Björn Nordlund ${ }^{5,6}$, Katrine D. Sjøborg ${ }^{10}$, Håvard O. Skjerven ${ }^{1,2}$, Anne C. Staff ${ }^{1,4}$, \\ Cilla Söderhäll ${ }^{6}$, Riyas M. Vettukatil (10) ${ }^{1,2}$ and Karin C. Lødrup Carlsen ${ }^{1,2}$ \\ on behalf of the PreventADALL study group ${ }^{11}$
}

Affiliations: ${ }^{1}$ Faculty of Medicine, Institute of Clinical Medicine, University of Oslo, Oslo, Norway. ${ }^{2}$ Division of Paediatric and Adolescent Medicine, Oslo University Hospital, Oslo, Norway. ${ }^{3}$ Dept of Toxicology and Risk Assessment, Norwegian Institute of Public Health, Oslo, Norway. "Division of Obstetrics and Gynaecology, Oslo University Hospital, Oslo, Norway. ${ }^{5}$ Astrid Lindgren Children's Hospital, Karolinska University Hospital, Stockholm, Sweden. 'Dept of Women's and Children's Health, Karolinska Institute, Stockholm, Sweden. ${ }^{7}$ Faculty of Chemistry, Biotechnology and Food Science, Norwegian University of Life Sciences, Ås, Norway. ${ }^{8}$ Genetic Unit, Centre for Laboratory Medicine, Østfold Hospital Trust, Kalnes, Norway. ${ }^{9}$ VID Specialized University, Oslo, Norway. ${ }^{10}$ Dept of Obstetrics and Gynaecology, Østfold Hospital Trust, Kalnes, Norway. ${ }^{11}$ For a list of the PreventADALL study group members and their affiliations see the Acknowledgements section.

Correspondence: Ina Kreyberg, Division of Paediatrics and Adolescent Medicine, Oslo University Hospital and the University of Oslo, Postboks 4956 Nydalen, 0424 Oslo, Norway. E-mail: inakreybergahotmail.com

ABSTRACT In young women, the use of snus increases in parallel with decreasing smoking rates but the use in pregnancy is unclear. Our aims were to determine the prevalence of snus use, smoking and other nicotine-containing product use during pregnancy, and to identify predictors for snus use in pregnancy.

Prevalence was determined for 2528 women in Norway and Sweden based on the Preventing Atopic Dermatitis and ALLergies (PreventADALL) study, a population-based, mother-child birth cohort. Electronic questionnaires were completed in pregnancy week 18 and/or week 34, and potential predictors of snus use were analysed using logistic regression models.

Ever use of any snus, tobacco or nicotine-containing products was reported by $35.7 \%$ of women, with similar rates of snus use (22.5\%) and smoking (22.6\%). Overall, $11.3 \%$ of women reported any use of nicotine-containing products in pregnancy up to 34 weeks, most often snus alone (6.5\%). Most women $(87.2 \%)$ stopped using snus by week 6 of pregnancy.

Snus use in pregnancy was inversely associated with age and positively associated with urban living and personal or maternal history of smoking. While $11.3 \%$ of women used snus or other nicotine-containing products at some time, most stopped when recognising their pregnancy. Younger, urban living, previously smoking women were more likely to use snus in pregnancy.

@ERSpublications

Of the $11.3 \%$ of women using any nicotine products in pregnancy (most often snus $(6.5 \%)$ ), the majority stop within pregnancy week 6 . Snus use is associated with urban living, previous smoking, in utero smoking exposure of the index woman and lower age. http://ow.ly/Gyg230nmxIo

Cite this article as: Kreyberg I, Bains KES, Carlsen K-H, et al. Stopping when knowing: use of snus and nicotine during pregnancy in Scandinavia. ERJ Open Res 2019; 5: 00197-2018 [https://doi.org/ 10.1183/23120541.00197-2018].

This article has supplementary material available from openres.ersjournals.com.

Received: Oct 242018 | Accepted after revision: Dec 262018

This study is registered at www.clinicaltrials.gov with identifier number NCT02449850. No individual participant data will be available for sharing.

The study was performed within ORAACLE (the Oslo Research Group of Asthma and Allergy in Childhood; the Lung and Environment)

Copyright $\odot$ ERS 2019. This article is open access and distributed under the terms of the Creative Commons Attribution Non-Commercial Licence 4.0. 


\section{Introduction}

The risk of adverse health effects in offspring due to maternal tobacco smoking during pregnancy is well documented [1], including epigenetic changes persisting in the offspring after prenatal exposure [2]. The effects of fetal exposure to nicotine from non-combustible tobacco products, such as snus or nicotinereplacement therapies (NRTs), are less clear. Use of snus leads to systemic absorption of nicotine into the maternal circulatory system, with subsequent exposure of the foetus through the placenta [3]. Recent register studies suggest that compared to non-tobacco users snus use alone in pregnancy increases the risk of stillbirth [4], preterm delivery [5] and small size for gestational age (GA) [6]. In addition, fetal nicotine exposure in animal models has shown altered pulmonary development and health in offspring [7], as well as epigenetic changes [8].

A substantial shift in the use of nicotine-containing products has recently been observed in many parts of the world, particularly among the young. In the United States the overall use of any tobacco or nicotine products reported by high school students in 2016 (20.2\%) was similar to 5 years earlier, however, the use of electronic cigarettes (e-cigarettes) increased from $1.5 \%$ to $11.3 \%$ while combustible tobacco use decreased from $21.8 \%$ to $13.8 \%$ [9]. Similar shifts from smoking towards the use of other nicotine products are observed in many Western countries [10-12], as shown by $29.9 \%$ of Polish youths reporting the use of e-cigarettes in 2014 [11] and e-cigarettes being almost twice as common as smoking among youths in Wales [12]. While e-cigarettes have been banned [13,14] and infrequently used [15] in Norway and Sweden, the shift from smoking has rather been towards snus which has been available for many years. Snus, also termed moist snuff, is smokeless, ground tobacco placed between the gum and the lip [3]. Compared to cigarettes, snus gives a slower rise in nicotine plasma levels but a higher total concentration over time [16]. In 2010, a 10-fold higher rate of snus use was reported in Sweden compared to other European countries, where snus sales are limited [17]. From 2008 to 2017 the use of snus increased among women in Norway, with daily snus use increasing from 5\% to $14 \%$ among $16-24$ year olds and from $1 \%$ to $12 \%$ among $25-34$ year olds [18].

The use of nicotine-containing products among young women is likely to be reflected in their use during pregnancy, as seen with declining smoking rates in some countries which are also being reported during pregnancy [19, 20]. Apart from register studies from Sweden [5], Norway [21] and the United States [22], there is limited updated information on the use of other nicotine products (such as snus and NRTs) in pregnancy. A recent study from Norway demonstrated a doubling of "daily" or "sometimes" snus use at the start of pregnancy between 2012 and 2014, from $1.7 \%$ to $3.4 \%$, with the highest rates among the 16-24 year olds [21].

In pregnancy, single women smokers with lower educational levels have the highest smoking prevalence $[23,24]$ and the lowest smoking decline since 1999 [24]. While risk factors for snus use during pregnancy are largely unknown, educational level has not in general been clearly associated with snus use [25, 26]. However, lower economic status [27], younger age, higher alcohol consumption, number of sexual partners and heavy physical activity [26] have been.

Limited knowledge of the potential harmful effects of snus use in pregnancy, the alleged harm reduction of snus use compared to smoking and animal studies suggesting that fetal exposure to nicotine is similar in both snus and cigarette use, raise concerns about the continuing, albeit changing, patterns of nicotine use by young women. The primary aim of the present study was therefore to determine the prevalence of snus and other nicotine-containing product use during pregnancy. The secondary aim was to identify factors associated with the use of snus.

\section{Subjects and methods}

Study design

The present study used data from the Preventing Atopic Dermatitis and ALLergies (PreventADALL) study [28], a large population-based, prospective mother-child birth cohort. Briefly, between December 2014 and October 2016, 2697 women with a total of 2701 pregnancies were recruited from general, nonselected populations in Norway (2149 from Oslo University Hospital and Østfold Hospital Trust) and Sweden (552 from the Karolinska Institutet, Stockholm) at the routine ultrasound screening examination in gestational week 18. Inclusion criteria were single and twin pregnancies at weeks $16-22$ and sufficient Scandinavian language skills. Exclusion criteria were severe maternal or fetal disease or the parents planning to move away from the area within the baby's first year of life. Healthy infants born at a GA of at least 35.0 weeks were enrolled at birth, constituting 2397 mother-child pairs [28].

The enrolment visit included obtaining written informed consent, measures of height and weight, a brief interview on the present and previous pregnancies, and information on how to complete the electronic questionnaires at 18 and 34 weeks. 
The PreventADALL study was approved by the Regional Committee for Medical and Health Research Ethics in South-Eastern Norway (2014/518) and in Sweden (2014/2242-31/4), and the study was registered at ClinicalTrials.gov (number NCT02449850).

\section{Subjects}

The present study included all 2528 women who completed at least one of two electronic questionnaires. The overall mean age among the 1985 women enrolled in Norway and the 543 women in Sweden was 32.4 years (range $20-48$ years) as shown in table 1 and supplementary table S1.

\section{Methods}

The electronic questionnaires, developed in collaboration with the University Center for Information Technology (USIT) at the University of Oslo [28], included detailed questions about all types of tobacco

\begin{tabular}{|c|c|c|}
\hline \multirow[t]{2}{*}{ Characteristics } & \multicolumn{2}{|c|}{ Inclusion in the present analysis } \\
\hline & Yes $^{\#}(n=2528)$ & $\mathrm{No}^{\#}(\mathrm{n}=173)$ \\
\hline Maternal age years & $32.4(20-48)^{\uparrow}$ & $31.1(18-44)^{9}$ \\
\hline \multicolumn{3}{|l|}{ Maternal data } \\
\hline BMI before pregnancy $(n=2460)$ & $23.2(13.8-45.7)$ & $23.6(17.1-44.1)$ \\
\hline Height $\mathrm{cm}(\mathrm{n}=2491)$ & $168.0(147.0-187.0)$ & $167.4(147.0-186.0)$ \\
\hline Weight before pregnancy kg ( $\mathrm{n}=2471)$ & $65.4(42.5-126.0)$ & $64.2(42.0-116.0)$ \\
\hline Weight at inclusion $\mathrm{kg}(\mathrm{n}=2498)$ & $70.2(44.8-132.7)$ & $68.0(45.8-117.0)$ \\
\hline Previous pregnancy & $1292(51.1)$ & \\
\hline \multicolumn{3}{|l|}{ Previous pregnancies $^{+}(n=2528)$} \\
\hline 0 & 1236 (48.9) & \\
\hline 1 & $652(25.8)$ & \\
\hline 2 & $377(14.9)$ & \\
\hline 3 & $143(5.7)$ & \\
\hline$>3$ & $120(4.8)$ & \\
\hline \multicolumn{3}{|l|}{ Education ( $n=2350$ ) } \\
\hline Preliminary school only (9-10 years) & $18(0.8)$ & \\
\hline High school only & 239 (10.2) & \\
\hline Higher education $<4$ years & 758 (32.2) & \\
\hline Higher education $\geqslant 4$ years & $1324(56.3)$ & \\
\hline Other & $2(0.1)$ & \\
\hline Unknown & $9(0.4)$ & \\
\hline \multicolumn{3}{|l|}{ Country of origin ( $n=2350$ ) } \\
\hline Norway & $1562(66.5)$ & \\
\hline Sweden & $523(22.3)$ & \\
\hline Other nordic & $31(1.3)$ & \\
\hline Rest of the world & $234(10.0)$ & \\
\hline \multicolumn{3}{|l|}{ Marital status ( $n=2350$ ) } \\
\hline Married & $968(41.2)$ & \\
\hline Cohabitant & $1313(55.9)$ & \\
\hline Single & $44(1.9)$ & \\
\hline Divorced/separated & $1(0.04)$ & \\
\hline Other & $24(1.0)$ & \\
\hline \multicolumn{3}{|l|}{ Living environment ( $n=2350$ ) } \\
\hline City (densely populated) & $916(39.0)$ & \\
\hline City (less densely populated) & 882 (37.5) & \\
\hline Suburb & 373 (15.9) & \\
\hline Countryside (in village) & $127(5.4)$ & \\
\hline Countryside (outside village) & $52(2.2)$ & \\
\hline
\end{tabular}

Data is presented as mean (min-max) or $\mathrm{n}(\%)$. BMI: body mass index. " : subjects were included in the present analysis if one or more questionnaires (from 18 weeks and 34 weeks) was completed. Subjects were excluded if questionnaires were not completed. Total pregnancies at 18 weeks available for inclusion was 2701. Total questionnaires completed at 18 weeks was $2350 .{ }^{~}$ : $p<0.001 ;{ }^{+}$: number of reported pregnancies excluding the current pregnancy. 
and nicotine use prior to and during pregnancy. The questionnaires were sent at a fixed time related to the inclusion date (between the 16th and 22nd weeks of pregnancy), with an automatic reminder in case of no response. The women specified their perceived week of pregnancy when completing the questionnaires. The 18-week questionnaire included questions about ever use (daily or sometimes) of any tobacco or nicotine product prior to and during pregnancy up to the time of completing the questionnaire, while the 34-week questionnaire asked about any use in the period since completing the previous questionnaire.

The questions regarding ever use of tobacco- or nicotine-containing products had separate detailed follow-up questions for cigarette smoking and snus use, included the time of use ("stopped years before pregnancy", "stopped in the time before pregnancy", "stopped when recognising pregnancy" or "current use in pregnancy"), with further details of use in pregnancy or the week of pregnancy when stopping as outlined in the supplementary material. There were no questions specifically determining if cessation was in relation to antenatal visits.

\section{Outcomes, definitions and explanatory variables}

The main outcome was use of any nicotine-containing products such as snus, tobacco cigarettes, NRTs and e-cigarettes during pregnancy. The main outcome was further reported for snus, smoking or dual users reported as mutually exclusive categories, unless otherwise specified. Additional nicotine-containing products included "e-cigarettes", "cigars/cigarillos", "pipes" or "other", while NRTs were categorised as "patches” or "gums/lozenges/sprays".

To explore factors related to the use of snus in pregnancy, we included variables that have been associated with smoking: country of origin, living environment, marital status, education level, total household income, previous or current cigarette smoking, the index woman being exposed to maternal smoking in utero, household cigarette smoking, age, pre-pregnancy body mass index (BMI), and number of previous pregnancies (excluding current pregnancy) and deliveries.

\section{Statistical analysis}

Categorical variables are presented in numbers and percentages, and continuous variables as mean values with maximum and minimum ranges. To address the rates of stopping use of nicotine-containing products in pregnancy, we used data from all 2187 subjects who completed both questionnaires.

Differences between categorical variables were analysed by Chi-squared tests and numerical data by t-tests or one-way ANOVA tests. Binary logistic regression was used to determine factors that might be associated with the use of snus in pregnancy by first excluding potential covariates with a p-value greater than 0.25. The significance level was set to 0.05 and all analyses were performed using IBM SPSS statistics version 25 (Chicago, IL, USA).

\section{Results}

Of the 2528 women who completed at least one questionnaire, 2350 completed the 18 -week questionnaire, 2365 completed the 34 -week questionnaire and 2187 completed both. The included women were similar to those who did not complete any of the questionnaires, with the exception of a slightly higher age (table 1). Background characteristics given by study location are described in supplementary table S1. The use of nicotine-containing products prior to pregnancy is given in table 2 , in the supplementary material and in supplementary figure S1.

\section{Prevalence}

Based on the women who completed at least one of the 18- or 34-week questionnaires, any use of tobaccoor nicotine-containing products at some time during pregnancy was reported by 286 out of 2528 subjects (11.3\%). Snus use alone was reported in $6.5 \%$ of cases, cigarette smoking alone in $4.1 \%$ of cases, dual use in $0.6 \%$ of cases and use of NRTs/e-cigarettes in $0.2 \%$ of cases.

From the 18-week questionnaire, any use of tobacco- or nicotine-containing products until pregnancy week 18 was reported by 284 out of 2350 of subjects overall (12.1\%), with $12.5 \%$ reported in Norway and $10.7 \%$ reported in Sweden. Use of Snus alone was the most common form of nicotine-containing product use, reported by $6.9 \%$ of subjects, while $4.3 \%$ reported smoking alone and $0.6 \%$ were dual users. Snus use (including dual use) at some time during pregnancy was $7.6 \%$ in total and significantly more common in Norway than in Sweden (8.2\% versus 5.5\%; $\mathrm{p}=0.035)$, as shown in table 2 and supplementary figure S1.

Current use of any nicotine-containing products at pregnancy week 18 was reported by 33 out of 2350 subjects $(1.4 \%$ ), with $0.6 \%$ using only snus and $0.8 \%$ being current smokers only. None reported current dual use, as shown in table 2 and supplementary figure S1. Most current snus users were daily users of three to six portions, a portion being a sealed pouch of snus (see the supplementary material for further 


\begin{tabular}{|c|c|c|c|c|}
\hline Parameter & Total & Norway & Sweden & p-value ${ }^{\#}$ \\
\hline \multicolumn{5}{|l|}{ Questionnaire adherence } \\
\hline Completed at 18 weeks & $2350(100.0)$ & $1818(77.4)$ & $532(22.6)$ & \\
\hline Completed 34 weeks & $2365(100.0)$ & $1853(78.4)$ & $512(21.7)$ & \\
\hline Completed one or more & $2528(100.0)$ & 1985 (78.5) & 543 (21.5) & \\
\hline Completed both & $2187(100.0)$ & $1686(77.1)$ & $501(22.9)$ & \\
\hline \multicolumn{5}{|l|}{ Tobacco habits } \\
\hline \multicolumn{5}{|l|}{ Ever use in life ( $n=2350$ ) } \\
\hline All nicotine-containing products & $840(35.7)$ & $680(37.4)$ & $160(30.1)$ & 0.002 \\
\hline Snus & $529(22.5)$ & $434(23.9)$ & 95 (17.9) & 0.003 \\
\hline Cigarette smoke & $531(22.6)$ & $423(23.3)$ & 108 (20.3) & 0.15 \\
\hline \multicolumn{5}{|l|}{ Use before pregnancy $(n=2350)$} \\
\hline \multicolumn{5}{|l|}{ Stopped years before pregnancy } \\
\hline Snus & $213(9.6)$ & $165(9.1)$ & $48(9.0)$ & 0.97 \\
\hline Cigarette smoke & $338(14.4)$ & $276(15.2)$ & $62(11.7)$ & 0.04 \\
\hline \multicolumn{5}{|l|}{ Stopped in the time before pregnancy } \\
\hline Snus & 138 (5.9) & $120(6.6)$ & $18(3.4)$ & 0.005 \\
\hline Cigarette smoke & 77 (3.3) & $65(3.6)$ & $12(2.3)$ & 0.13 \\
\hline \multicolumn{5}{|l|}{ Snus in pregnancy (including dual users) } \\
\hline At some time up to 18 weeks $(n=2350)$ & $178(7.6)$ & 149 (8.2) & $29(5.5)$ & 0.035 \\
\hline Current use at 18 weeks & $13(0.6)$ & $11(0.6)$ & $2(0.4)$ & 0.81 \\
\hline Stopped when recognising pregnancy & $165(7.0)$ & $138(7.6)$ & $27(5.1)$ & \\
\hline At some time from $18-34$ weeks ( $n=2365$ ) & $18(0.8)$ & $14(0.8)$ & 4 (0.8) & 0.95 \\
\hline Current use at 34 weeks & 6 (0.3) & $4(0.2)$ & $2(0.4)$ & \\
\hline Stopped between 18 and 34 weeks & $12(0.5)$ & $10(0.5)$ & $2(0.4)$ & \\
\hline \multicolumn{5}{|c|}{ Cigarette smoke in pregnancy (including dual users) } \\
\hline At some time up to 18 weeks $(n=2350)$ & $116(4.9)$ & $82(4.5)$ & $34(6.4)$ & 0.08 \\
\hline Current use at 18 weeks & $18(0.8)$ & $14(0.8)$ & $4(0.8)$ & 0.84 \\
\hline Stopped when recognising pregnancy & $98(4.2)$ & $68(3.7)$ & $30(5.6)$ & \\
\hline At some time from $18-34$ weeks ( $n=2365$ ) & $14(0.6)$ & $10(0.5)$ & 4 (0.8) & 0.53 \\
\hline Current use at 34 weeks & $8(0.3)$ & $6(0.3)$ & $2(0.4)$ & \\
\hline Stopped between 18 and 34 weeks & $6(0.3)$ & $4(0.2)$ & $2(0.4)$ & \\
\hline \multicolumn{5}{|l|}{ Dual snus and cigarette smoke in pregnancy } \\
\hline At some time up to 18 weeks $(n=2350)$ & $15(0.6)$ & $7(0.4)$ & $8(1.5)$ & 0.004 \\
\hline Current use at 18 weeks & 0 & 0 & 0 & \\
\hline Stopped when recognising pregnancy & $15(0.6)$ & $7(0.4)$ & $8(1.5)$ & \\
\hline At some time from $18-34$ weeks $(n=2365$ ) & $1(0.04)$ & 0 & $1(0.2)$ & \\
\hline Current use at 34 weeks & 0 & 0 & 0 & \\
\hline Stopped between 18 and 34 weeks & $1(0.04)$ & 0 & $1(0.2)$ & \\
\hline \multicolumn{5}{|l|}{ NRTs/e-cigarettes in pregnancy } \\
\hline At some time up to 18 weeks $(n=2350)$ & $5(0.2)$ & $3(0.2)$ & $2(0.4)$ & \\
\hline Current use at 18 weeks & $2(0.1)$ & $1(0.1)$ & $1(0.2)$ & \\
\hline Stopped when recognising pregnancy & $3(0.1)$ & $2(0.1)$ & $1(0.2)$ & \\
\hline At some time from $18-34$ weeks ( $n=2365$ ) & $1(0.1)$ & 0 & $1(0.2)$ & \\
\hline Current use at 34 weeks & $1(0.1)$ & 0 & $1(0.2)$ & \\
\hline Stopped between 18 and 34 weeks & 0 & 0 & 0 & \\
\hline
\end{tabular}

details). The use of NRTs or e-cigarettes was uncommon until 18 weeks $(0.2 \%)$, with two pregnant women using nicotine gum and three using e-cigarettes. Of these women, four were previously cigarette smokers or snus users.

Overall, $1.3 \%$ of the 2365 women completing the 34-week questionnaire reported use of any tobacco- and nicotine-containing products in late pregnancy (defined as from 18 to 34 weeks). At pregnancy week 34, $0.3 \%$ were current snus users only and $0.3 \%$ were current cigarette smokers only (see table 2 and supplementary figure S1). None of the women reported current use of NRTs and only one woman $(0.04 \%)$ reported use of e-cigarettes at some time between 18 and 34 weeks of pregnancy.

Based on reports from the 2187 women who completed both questionnaires, 245 out of 269 (91.1\%) of the women using snus $(n=164)$ and/or cigarettes $(n=105)$ at some time while pregnant stopped as soon as they 
became aware of their pregnancy. As illustrated in figure 1 for snus and smoking, 143 out of 164 (87.2\%) quit snus and 83 out of $105(79.1 \%)$ quit smoking by pregnancy week six. Only five women reported use of NRTs or e-cigarettes until pregnancy week 18, of whom three reported quitting at recognised pregnancy. Relapse was generally uncommon, with details given in the supplementary material.

\section{Factors associated with use of snus in pregnancy}

From our final multiple logistic regression analyses (Nagelkerke), we could explain 15\% of snus use (including dual cigarette smoking) in pregnancy based upon the significant predictors shown in figure 2. The adjusted, significant predictors included inverse association with age, a positive association with urban living (see supplementary figure S2 for details), cohabiting with the partner rather than being married (as is common in Norway and Sweden), being native born in Norway or Sweden compared to elsewhere, previous or current smoking history and the index women being exposed to smoking in utero. Maternal education, household income, household smoking, pre-pregnancy BMI and the number of reported previous pregnancies and deliveries were not significantly associated with the use of snus during pregnancy.

\section{Discussion}

In this prospective mother-child birth cohort study from 2014, $11.3 \%$ of the women reported use of any type of tobacco- or nicotine-containing product at some time during pregnancy up to 34 weeks. Use of snus alone was most common (reported by $6.5 \%$ of women), followed by smoking only (4.1\%), dual use $(0.6 \%)$ and NRTs or e-cigarettes $(0.2 \%)$. However, most women stopped when recognising their pregnancy, with $87.2 \%$ of snus users and $79.1 \%$ of smokers quitting by pregnancy week six. Snus use in pregnancy was inversely associated with age and positively associated with urban living, being a cohabitant compared to being married or a single mother, being native born in Norway or Sweden compared to other countries, having a personal smoking history and being exposed to cigarettes in utero.

The $4.7 \%$ of women smoking during pregnancy (including $0.6 \%$ dual use) is much lower than rates in similar birth cohort studies from Norway and Sweden around 25 years ago, with a $27 \%$ smoker rate in the Environment and Childhood Asthma (ECA) study [29] and a 13\% rate in the Swedish BAMSE study [30].

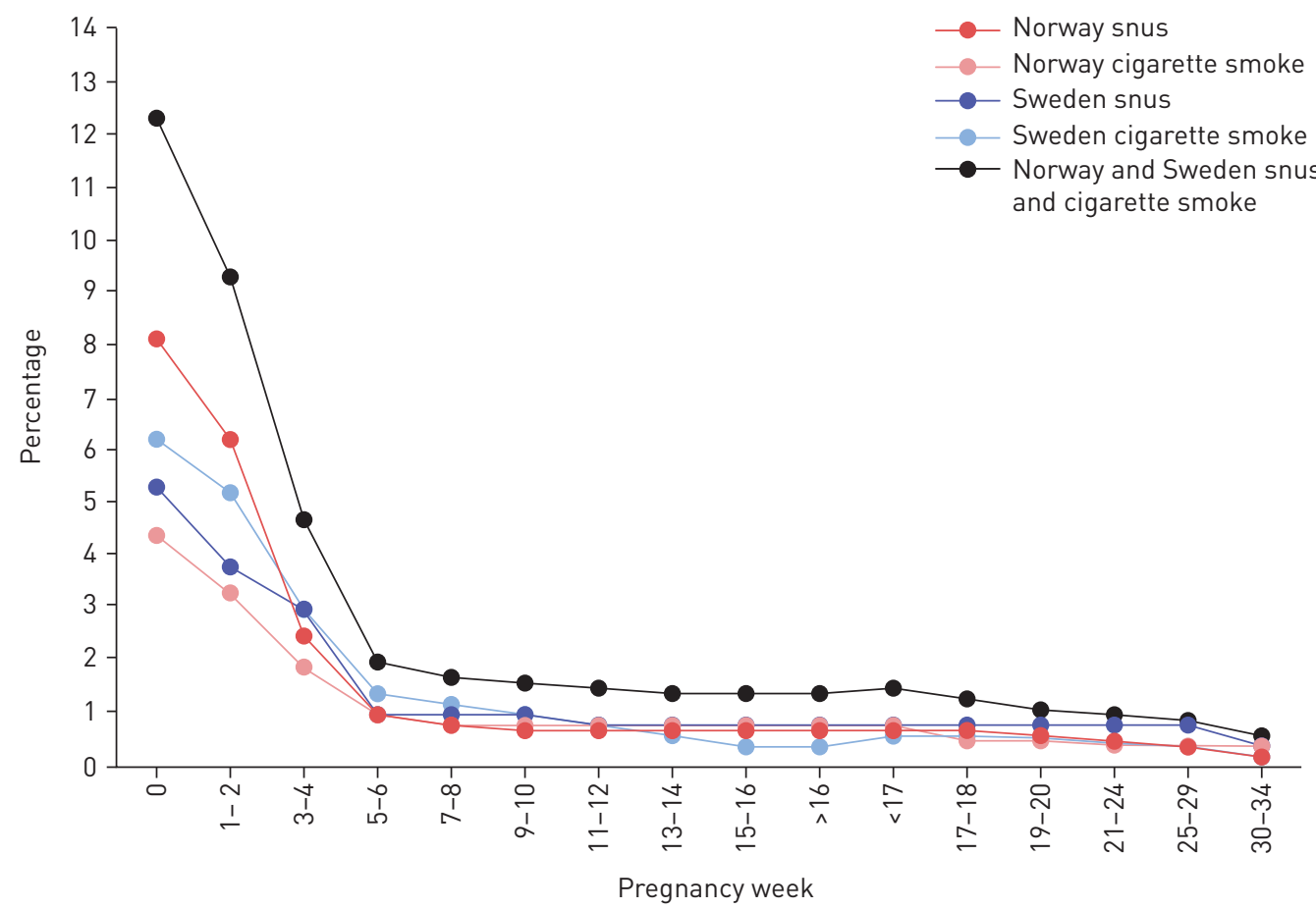

FIGURE 1 Percentage of women using snus and/or cigarette smoke during pregnancy based on self-reported time for stopping from those who completed both 18-week and 34-week questionnaires ( $n=2187$ ). Time for stopping categories were from 1-2 weeks to $>16$ weeks and from $<17$ weeks to $30-34$ weeks, respectively. Among the women who reported the use of snus, cigarette smoke or dual use at some time during pregnancy, most stopped when they recognised their pregnancy (mean pregnancy week three to four). Week 0 reflects the total percentage of women who reported any use during pregnancy. E-cigarettes and nicotine replacement therapies were not included since the rates were low. 


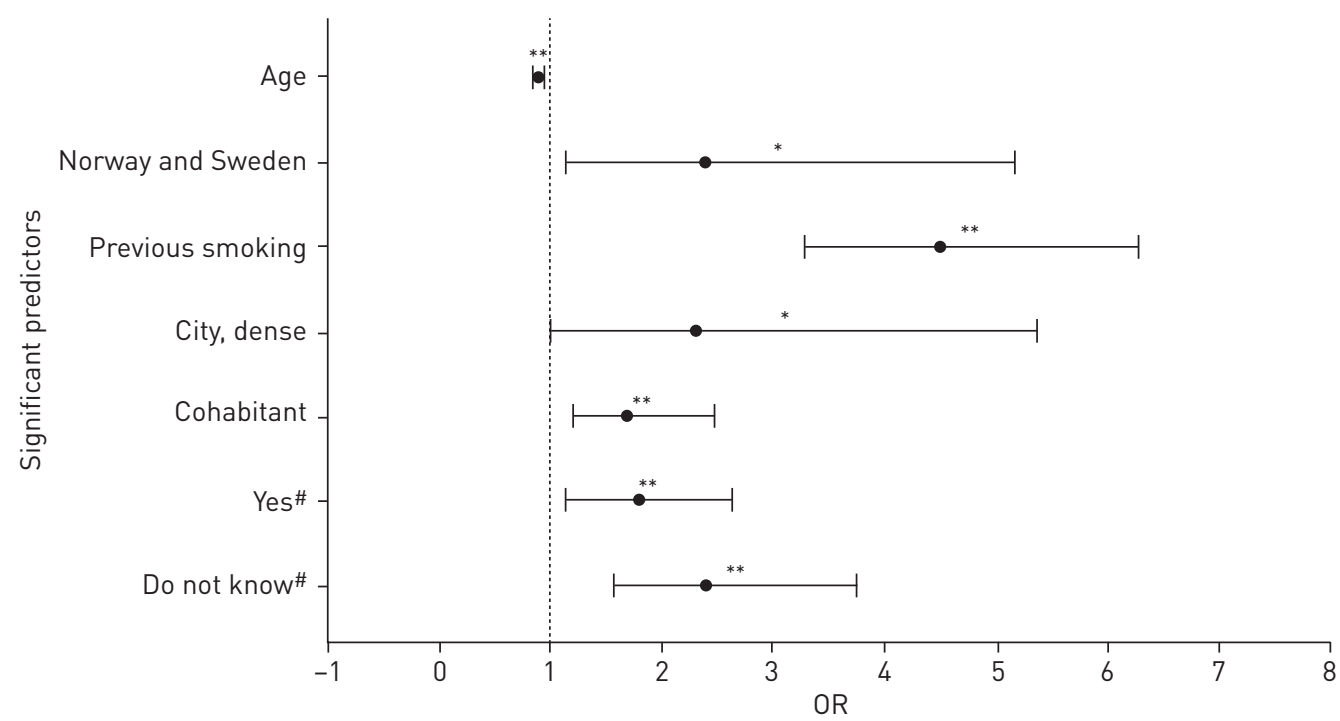

FIGURE 2 Factors associated with snus use during pregnancy. In multivariate analysis, the following factors were identified as associated with the use of snus at some time during pregnancy (reference categories are presented in italic for each factor): living area (countryside (village) versus city (densely populated), city (less densely populated), suburb, countryside (outside village)); grand maternal cigarette smoking (no versus yes, do not know); country of origin (rest of the world and other nordic countries combined versus Norway or Sweden); previous and/or current smoking (no versus yes); marital status (married versus cohabitant, single, divorced/separated, other). Age was used as a continuous variable. OR: odds ratio. " : in utero smoking exposure of the index woman; *: $p<0.05 ;{ }^{* *}: p<0.01$.

This favourable change harmonises with the decrease in overall smoking rates among pregnant women and the population in general, a trend seen in some $[19,20]$ but not all $[31,32]$ countries in the past decades. In contrast, snus use in pregnancy has been largely unknown until recently. The $7.6 \%$ of women using snus at some time until week 18 of pregnancy (including $0.6 \%$ dual use) is somewhat higher than recent registry studies from Norway [21] and Sweden [33]. The 8.2\% of pregnant Norwegian women reporting snus use in our study (including $0.4 \%$ dual use) is substantially higher than the $3.4 \%$ of first trimester snus use recorded in 2014 that was obtained from a hospital register in Southern Norway [21]. Likewise, the $5.5 \%$ of snus use during pregnancy in the Swedish part of our study (including $1.5 \%$ dual use) exceeded the $1.2 \%$ of snus use in early pregnancy reported in the Swedish Birth Register in 2016 [33]. However, the rate of snus use alone in late pregnancy $(0.3 \%)$ was similar to the Norwegian and Swedish registries [21,33]. The higher rates among pregnant women reported in our study, with data recorded from 2014 to 2016, probably reflect the recent rapid increase in snus use among young women [27]. The low prevalence of NRT and e-cigarette use in the present study is, to the best of our knowledge, not previously reported. It should also be noted that we collected data only on tobacco and nicotine products available in Scandinavia and thus products such as "hookah" are not reported.

That the majority of women stopped using snus or stopped smoking by week six of pregnancy is good news and has to our knowledge not been reported previously. It is in line with the reported drop in the prevalence of snus use from early to late pregnancy in the Swedish and Norwegian birth registries [21, 33]. A growing body of evidence demonstrates that the beginning of life, including the time before conception, during pregnancy and in infancy, is a critical period in setting the trajectory towards an increased risk of non-communicable diseases [34]. As epigenetic changes are likely to impact developmental programming in the context of Developmental Origins of Health and Disease (DOHaD) [35], avoiding nicotine overall, even before recognising pregnancy, is important. In this study, the early "stopping when knowing" that is likely to occur even before the first antenatal visit suggests an active choice to abstain from potentially harmful exposure to the unborn child.

The inverse association of snus use with age, the positive association with urban living and lack of association with educational attainment in our study differ from the lower educational level seen among smokers [36]. However, our predictors for snus use appear more similar to non-daily smokers than daily smokers in terms of educational level, income, marital status, weight and the rate of spontaneously quitting in early pregnancy [37]. The explained variation in predictors of snus use in pregnancy was only $15 \%$, but was quite similar to predictors of smoking in pregnancy [38]. In this study, previous smoking history and exposure to maternal prenatal smoking were factors associated with using snus in pregnancy. 
This corresponds with a study demonstrating an intergenerational association of mothers' and daughters' smoking habits during pregnancy, indicating that daughters exposed in utero were more likely to smoke when pregnant than unexposed daughters [39]. Though the mechanism behind this is multifactorial and likely includes behavioural, (epi)genetic and environmental factors [39], it suggests a nicotine susceptibility affecting the risk of use in pregnancy.

The present study is strengthened by its prospective design, with a high follow-up rate where detailed information on tobacco and nicotine use is reported twice during pregnancy. The higher educational attainment level in our study compared to society at large [28] is unlikely to impact the observed prevalence rates, as maternal education was not associated with snus use and our findings largely reflect the rapidly changing societal use of snus. The under-reporting of the use of tobacco products cannot be excluded in this questionnaire-based study, nor did we have biological assays to confirm nicotine exposure. However, self-reported data may be sufficiently accurate as a high degree of association between self-reported tobacco use and nicotine exposure, as assessed by blood cotinine drawn at delivery, has been found [40]. Our data showed a higher prevalence than previously reported from a national health register [21], suggesting that under-reporting may be limited in this prospective study.

\section{Conclusion}

In the present study, the $11.3 \%$ use of tobacco- and nicotine-containing products during pregnancy was lower than two decades ago, but the prevalence of snus use alone $(6.5 \%)$ was higher than in recent registry reports. Of snus users, $87.2 \%$ quit by week six of pregnancy. Snus use in pregnancy was inversely associated with age and was more common among urban living, cohabitating women with a personal or maternal history of smoking.

In order to give appropriate advice to pregnant women there is an urgent need for large prospective studies investigating potential harmful effects on offspring following the use of non-combustible nicotine products in pregnancy. In the meanwhile, the precautionary principle should be advocated for all types of tobacco and nicotine products in pregnancy.

Acknowledgements: We sincerely thank the study participants and the health personnel who contributed to the recruitment and inclusion of the subjects.

The PreventADALL study group: Anna Asarnoj (Astrid Lindgren Children's Hospital, Karolinska University Hospital, and Dept of Women's and Children's Health, Karolinska Institutet, Stockholm, Sweden), Oda C. Lødrup Carlsen (Division of Paediatric and Adolescent Medicine, Oslo University Hospital, Oslo, Norway), Kim A. Endre (Faculty of Medicine, Institute of Clinical Medicine, University of Oslo, and Division of Paediatric and Adolescent Medicine, and Dept of Dermatology, Oslo University Hospital, Oslo, Norway), Peder A. Granlund (Faculty of Medicine, Institute of Clinical Medicine, University of Oslo, and Division of Paediatric and Adolescent Medicine, Oslo University Hospital, Oslo, Norway), Henrik Holmstrøm (Faculty of Medicine, Institute of Clinical Medicine, University of Oslo, and Division of Paediatric and Adolescent Medicine, Oslo University Hospital, Oslo, Norway), Geir Håland (Faculty of Medicine, Institute of Clinical Medicine, University of Oslo, and Division of Paediatric and Adolescent Medicine, Oslo University Hospital, Oslo, Norway), Caroline-Aleksi O. Mägi (Astrid Lindgren Children's Hospital, Karolinska University Hospital, and Dept of Women's and Children's Health, Karolinska Institutet, Stockholm, Sweden), Unni C. Nygaard (Dept of Toxicology and Risk Assessment, Norwegian Institute of Public Health, Oslo, Norway), Eva M. Rehbinder (Faculty of Medicine, Institute of Clinical Medicine, University of Oslo, and Division of Paediatric and Adolescent Medicine, and Dept of Dermatology, Oslo University Hospital, Oslo, Norway), Carina M. Saunders (Faculty of Medicine, Institute of Clinical Medicine, University of Oslo, and Division of Paediatric and Adolescent Medicine, Oslo University Hospital, Oslo, Norway), Ingebjørg Skrindo (Dept of Ear, Nose and Throat, Akershus University Hospital, Lørenskog, Norway), Sandra G. Tedner (Astrid Lindgren Children's Hospital, Karolinska University Hospital, and Dept of Women's and Children's Health, Karolinska Institutet, Stockholm, Sweden), Magdalena R. Værnesbranden (Faculty of Medicine, Institute of Clinical Medicine, University of Oslo, Oslo, and Dept of Obstetrics and Gynaecology, Østfold Hospital Trust, Kalnes, Norway) and Johanna Wiik (Dept of Obstetrics and Gynaecology, Østfold Hospital Trust, Kalnes, Norway, and Dept of Obstetrics and Gynaecology, Institute of Clinical Sciences, Sahlgrenska Academy, Gothenburg, Sweden).

Author contributions: All authors have contributed substantially to the design and/or clinical follow-up of the PreventADALL study, have revised the work critically for important intellectual content and approved the final version before submission. All members of the PreventADALL study group have contributed to the design and/or data collection, have revision the paper and approved the last version before submission.

Conflict of interest: B. Nordlund has nothing to disclose. K-H. Carlsen has received an honorarium for a lecture from Boehringer Ingelheim, outside the submitted work. A.C. Staff has nothing to disclose. C.M. Jonassen has nothing to disclose. L.S. Nordhagen has nothing to disclose. K.D. Sjøborg has nothing to disclose. G. Hedlin has nothing to disclose. H.K. Gudmundsdóttir has nothing to disclose. R.M. Vettukatil has nothing to disclose. C. Söderhäll has nothing to disclose. K. Hilde has nothing to disclose. H.O. Skjerven has nothing to disclose. K.E.S. Bains has nothing to disclose. B. Granum has nothing to disclose. G. Haugen has nothing to disclose. I. Kreyberg has nothing to disclose K.C. Lødrup Carlsen reports grants as declared in the support statement. She has also received an honorarium for a lecture at the EAACI conference in 2018 from ThermoFisher Scientific, as well as a speaker honorarium from ThermoFisher Scientific outside the submitted work. 
Support statement: The study was funded by the Regional Health Board South East, the Norwegian Research Council, Oslo University Hospital, the University of Oslo, Health and Rehabilitation Norway and Østfold Hospital Trust, and by unrestricted grants from the Norwegian Association of Asthma and Allergy, the Kloster Foundation, the Norwegian Society of Dermatology and Venerology, Arne Ingel's Legat, Fürst Medical Laboratory, the Foundation for Healthcare and Allergy Research in Sweden (Vårdalstiftelsen), the Swedish Asthma and Allergy Association's Research Foundation, the Swedish Research Council Initiative for Clinical Therapy Research, the Swedish Heart-Lung Foundation, SFO-V Karolinska Institutet, the Hesselman Research Foundation, Thermo-Fisher (Uppsala, Sweden; by supplying allergen reagents) and the European Union (MeDALL project). Funding information for this article has been deposited with the Crossref Funder Registry.

\section{References}

1 U.S. Department of Health and Human Services. The health consequences of smoking: 50 years of progress. A report of the surgeon general. Atlanta, U.S. Department of Health and Human Services, Centers for Disease Control and Prevention, National Center for Chronic Disease Prevention and Health Promotion, Office on Smoking and Health, 2014. www.ncbi.nlm.nih.gov/books/NBK179276/ Date last accessed: March 04, 2019.

2 Richmond RC, Suderman M, Langdon R, et al. DNA methylation as a marker for prenatal smoke exposure in adults. Int J Epidemiol 2018; 47: 1120-1130.

3 Scientific Committee on Emerging and Newly Identified Health Risks (SCENIHR), Health effects of smokeless tobacco products. Brussels, European Commission, 2008. http://ec.europa.eu/health/archive/ph_risk/committees/ 04_scenihr/docs/scenihr_o_013.pdf Date last accessed: March 04, 2019.

4 Baba S, Wikström AK, Stephansson O, et al. Influence of snuff and smoking habits in early pregnancy on risks for stillbirth and early neonatal mortality. Nicotine Tob Res 2014; 16: 78-83.

5 Dahlin S, Gunnerbeck A, Wikström AK, et al. Maternal tobacco use and extremely premature birth - a population-based cohort study. BJOG 2016; 123: 1938-1946.

6 Baba S, Wikström AK, Stephansson O, et al. Changes in snuff and smoking habits in Swedish pregnant women and risk for small for gestational age births. BJOG 2013; 120: 456-462.

7 Spindel ER, McEvoy CT. The role of nicotine in the effects of maternal smoking during pregnancy on lung development and childhood respiratory disease. Implications for dangers of e-cigarettes. Am J Respir Crit Care Med 2016; 193: 486-494.

8 Suter MA, Abramovici AR, Griffin E, et al. In utero nicotine exposure epigenetically alters fetal chromatin structure and differentially regulates transcription of the glucocorticoid receptor in a rat model. Birth Defects Res Part A Clin Mol Teratol 2015; 103: 583-588.

9 Jamal A, Gentzke A, Hu SS, et al. Tobacco use among middle and high school students - United States, 2011-2016. MMWR Morb Mortal Wkly Rep 2017; 66: 597-603.

10 WHO global report on trends in prevalence of tobacco smoking, Geneva, World Health Organization, 2015. https://apps.who.int/iris/bitstream/handle/10665/156262/9789241564922_eng.pdf; jsessionid=31D39C9C3D00534058403CEFB8FE54C8? sequence=1 Date last accessed: March 04, 2019.

11 Goniewicz ML, Gawron M, Nadolska J, et al. Rise in electronic cigarette use among adolescents in Poland. J Adolesc Health 2014; 55: 713-715.

12 de Lacy E, Fletcher A, Hewitt G, et al. Cross-sectional study examining the prevalence, correlates and sequencing of electronic cigarette and tobacco use among 11-16-year olds in schools in Wales. BMJ Open 2017; 7: e012784.

13 Cross-border or distance sales of tobacco and e-cigarettes in Norway. Norwegian Directorate of Health, 2018 https://helsedirektoratet.no/english/tobacco-control\#cross-border-or-distance-sales-of-tobacco-and-e-cigarettes-innorway Date last updated: February 09, 2018. Date last accessed: March 04, 2018.

14 Rules on tobacco products [Regler om tobaksvaror]. Public Health Agency of Sweden, 2018. www. folkhalsomyndigheten.se/livsvillkorlevnadsvanor/alkohol-narkotika-dopning-tobak-och-spel-andts/tobak/utvecklingenav-bruket/bruk-av-cigaretter-snus-oche-cigaretter-i-den-vuxna-befolkningen/ Date last updated: December 12, 2018 Date last accessed: March 04, 2019.

15 Prevalence of e-cigarettes and evaporators in Norway [Utbredelse av e-sigaretter og fordampere i Norge] Norwegian Institute of Public Health, 2018. www.fhi.no/nettpub/tobakkinorge/bruk-av-tobakk/utbredelse-av-esigaretter-og-fordampere-i-norge/ Date last updated: June 19, 2018. Date last accessed: March 04, 2019.

16 Digard H, Proctor C, Kulasekaran A, et al. Determination of nicotine absorption from multiple tobacco products and nicotine gum. Nicotine Tob Res 2013; 15: 255-261.

17 Leon ME, Lugo A, Boffetta P, et al. Smokeless tobacco use in Sweden and other 17 European countries. Eur J Public Health 2016; 26: 817-821.

18 Snus more used than cigarettes. Statistics Norway, 2018. www.ssb.no/en/helse/artikler-og-publikasjoner/snusmore-used-than-cigarettes Date last updated: January 18, 2018. Date last accessed: March 04, 2019.

19 Reitan T, Callinan S. Changes in smoking rates among pregnant women and the general female population in Australia, Finland, Norway, and Sweden. Nicotine Tob Res 2017; 19: 282-289.

20 Gender, women, and the tobacco epidemic. Geneva, World Health Organization, 2010. https://apps.who.int/iris/ bitstream/handle/10665/44342/9789241599511_eng.pdf?sequence=1 Date last accessed: March 04, 2019.

21 Rygh E, Gallefoss F, Reiso H. Use of snus and smoking tobacco among pregnant women in the Agder counties. Tidsskr Nor Laegeforen 2016; 136: 1351-1354.

22 Kurti AN, Redner R, Lopez AA, et al. Tobacco and nicotine delivery product use in a national sample of pregnant women. Prev Med 2017; 104: 50-56.

23 Härkönen J, Lindberg M, Karlsson L, et al. Education is the strongest socio-economic predictor of smoking in pregnancy. Addiction 2018; 113: 1117-1126.

24 Grøtvedt L, Kvalvik LG, Grøholt EK, et al. Development of social and demographic differences in maternal smoking between 1999 and 2014 in Norway. Nicotine Tob Res 2017; 19: 539-546.

$25 \varnothing$ Øerland S, Tjora T, Hetland J, et al. Associations between adolescent socioeducational status and use of snus and smoking. Tob Control 2010; 19: 291-296.

26 Kvaavik E, Lund I, Nygård M, et al. Lifestyle correlates of female snus use and smoking: a large population-based survey of women in Norway. Nicotine Tob Res 2016; 18: 431-436. 
Health risk when using snus [Helserisiko ved bruk av snus]. Norwegian Institute of Public Health, 2014. www.fhi. no/en/publ/2014/helserisiko-ved-bruk-av-snus/ Date last updated: August 10, 2016. Date last accessed: March 04, 2019.

28 Lødrup Carlsen, KC, Rehbinder EM, Skjerven HO, et al. Preventing Atopic Dermatitis and ALLergies in Children - the PreventADALL study. Allergy 2018; 73: 2063-2070.

29 Lødrup Carlsen KC, Jaakkola JJ, Nafstad P, et al. In utero exposure to cigarette smoking influences lung function at birth. Eur Respir J 1997; 10: 1774-1779.

30 Lannerö E, Kull I, Wickman M, et al. Environmental risk factors for allergy and socioeconomic status in a birth cohort (BAMSE). Pediatr Allergy Immunol 2002; 13: 182-187.

31 Smedberg J, Lupattelli A, Mårdby AC, et al. Characteristics of women who continue smoking during pregnancy: a cross-sectional study of pregnant women and new mothers in 15 European countries. BMC Pregnancy Childbirth 2014; 14: 213.

32 Tong VT, Dietz PM, Morrow B, et al. Trends in smoking before, during, and after pregnancy-pregnancy risk assessment monitoring system, United States, 40 sites, 2000-2010. MMWR Surveill Summ 2013; 62: 1-19.

33 Statistics database for pregnancies, deliveries and newborn infants [Statistikdatabas för graviditeter, förlossningar och nyfödda]. Swedish National Board of Health and Welfare, 2018. www.socialstyrelsen.se/statistik/statistikdatabas/ graviditeter-forlossningarochnyfodda Date last accessed: March 04, 2019.

34 Simeoni U, Armengaud JB, Siddeek B, et al. Perinatal origins of adult disease. Neonatology 2018; 113: $393-399$.

35 Bianco-Miotto T, Craig JM, Gasser YP, et al. Epigenetics and DOHaD: from basics to birth and beyond. J Dev Orig Health Dis 2017; 8: 513-519.

36 Penn G, Owen L. Factors associated with continued smoking during pregnancy: analysis of socio-demographic, pregnancy and smoking-related factors. Drug Alcohol Rev 2002; 21: 17-25.

37 Rockhill KM, Tong VT, England LJ, et al. Nondaily smokers' characteristics and likelihood of prenatal cessation and postpartum relapse. Nicotine Tob Res 2017; 19: 810-816.

38 Miguez MC, Pereira B, Figueiredo B. Tobacco consumption and spontaneous quitting at the first trimester of pregnancy. Addict Behav 2017; 64: 111-117.

39 Ncube CN, Mueller BA. Daughters of mothers who smoke: a population-based cohort study of maternal prenatal tobacco use and subsequent prenatal smoking in offspring. Paediatr Perinat Epidemiol 2017; 31: 14-20.

40 Mattsson K, Kållén K, Rignell-Hydbom A, et al. Cotinine validation of self-reported smoking during pregnancy in the Swedish medical birth register. Nicotine Tob Res 2016; 18: 79-83. 